\title{
O REGRESSO DO MORTO: REGRESSO À DesgraÇa de Suleiman Cassamo
}

\author{
Martins José Chelene Mapera
}

\begin{abstract}
RESUMO
O livro de contos O regresso do morto (1997), do escritor moçambicano Suleiman Cassamo, é uma obra que descreve a degradação do ser humano, marcando uma fronteira nítida entre a razão e a irracionalidade. Esta obra na qual o autor desenha um cenário melancólico enquadra-se no âmbito de textos de afirmação sociocultural. Através desta obra, cujos textos foram antologizados em manuais escolares de leitura obrigatória em Moçambique, mergulhamos na complexa e diversa realidade sociocultural moçambicana.
\end{abstract}

\section{PaLAVRas-chave}

Suleiman Cassamo; morte; desgraça; sociedade; casamento tradicional

\section{O REGRESSO DO MORTO: THE RETURN TO Misfortune by Suleiman Cassamo}

\begin{abstract}
The book of tales O regresso do morto [The return of the dead] (1997) by the Mozambican writer Suleiman Cassamo is a work that describes the degradation of the human being, marking a clear border between reason and irrationality. This work in which the author draws a melancholic scenario falls within the scope of texts of sociocultural affirmation. Through this work, whose texts were anthologized in compulsory reading textbooks in Mozambique, we immerse ourselves in the complex and diverse Mozambican sociocultural reality.
\end{abstract}

\section{KEYWORDS}

Suleiman Cassamo, death, misfortune, society, traditional marriage

No livro de contos O regresso do morto (1997), Suleiman Cassamo desenha um cenário melancólico, que começa com uma questionação terrível: "assim é viver?". Há, neste paródico questionamento, uma espécie de incerteza que paira na mente das personagens em relação ao destino quotidiano da vida. Cada dia que nasce parece uma incógnita irresoluta. Essa irresolução indicia a decorrência de uma paisagem de perplexidade que caracteriza o estado de alma de várias personagens, discernível nos diferentes contos da colectânea. 
A vida transformou-se num objecto inverosímil da subjectividade da narrativa e dos processos sociais que marcam a ficção pós-moderna'. Por isso, esta realidade subjectiva dos fenómenos sociais e antropológicos fez com que $O$ regresso do morto encontrasse um grande amparo da crítica moçambicana e internacional. A publicação francesa intitulada Le retour du mort, por exemplo, e o facto de os seus textos terem sido antologizados em manuais escolares de leitura obrigatória, em Moçambique, representam uma compilação emocional de verdades literárias em diferentes étapas da vida, numa logosfera social amplamente diversa.

Os contos intitulados "Ngilina, tu vai morrer", "Laurinda, tu vai mbunhar", "Nyeleti", "Madalena, xiluva do meu coração" e "O Regresso do morto" fazem uma grande recensão à desgraça, fecundada por um conjunto de personagens cujos nomes são antropologicamente significativos. Estas temáticas configuram o que poderia ser chamado lirismo pastoril, que mistura a tristeza e o amor, o odor e a nostálgia. Suleiman Cassamo escreve histórias sociais e não contos sociais. Dir-se-ia, com efeito, que as suas histórias transformam a "miséria em objecto de prazer", se quisermos emprestar as palavras do filósofo alemão Walter Benjamin (2012, p. 123), porquanto os contos da colectânea encerram um certo perfeccionismo estético.

O conto "Laurinda, tu vai mbunhar" é um exemplo claro de uma narrativa que ficciona um período histórico em que a sociedade viveu os momentos mais dramáticos da pós-independência, por causa de escassez generalizada de tudo. Foi um momento em que a posse era excepção à regra, e, por isso, questionada e criminalizada. Na década oitenta, Moçambique ficou tremendamente assolado pela fome e nudez, falta de transporte; o mercado era uma tela sem imagem para contemplar. Foi o momento das polémicas "bichas" ${ }^{2}$ nas lojas do povo, nas cooperativas de consumo, nos transportes, em tudo; o tempo em que se generalizou o fenómeno de casamentos prematuros, e os cooperantes e os "magaiça"3 eram as pessoas mais privilegiadas da sociedade. Vejamos os factos "historiográficos" seguintes, plasmados no conto "Nyeleti":

Nyeleti guardava para Foliche, o mais velho filho de Mahomo, seu corpo xonguile, de se partir e se juntar no andar de antílopes. Foliche voltava um dia feito gaiça. De Foliche, das suas malas e fardos de gaiça, o pai da Nyeleti queria fato e gravata, sapatos e hop-stick. Dele viria o mucume, o lenço para a Mabana, a mãe da Nyeleti, a nkeka e o frasco de rapé para a velha Magugu, mãe do pai de Nyeleti. (Cassamo, 1997, p. 29)

\footnotetext{
' Sobre a natureza do imaginário pós-moderno, e portanto, sobre a narrativa pós-moderna, escreveu Moisés de Lemos Martins, em 2011, "Media e melancolia - o trágico, o grotesco e o barroco". E especificamente sobre a narrativa da morte, Moisés de Lemos Martins escreveu, em 2013, "O corpo morto: mitos, ritos e superstições".

${ }^{2}$ As "bichas" são filas longas que se formavam para a compra de produtos de primeira necessidade, nas lojas do povo e nas cooperativas de consumo. Entretanto, havia, nessa altura, lojas especiais, reservadas para a alta nomenclartura do Estado, onde não se formavam as elásticas e imóveis "bichas". O músico moçambicano Jeremias Nguenha produziu uma música popularmente conhecida por "La famba bixa", ou seja, a fila vai; caminha lentamente, numa clara crítica ao modelo económico adoptado em Moçambique, a partir de manifestão folcórica.
}

3 Diz-se dos regressados das minas de África do Sul (Jone), que traziam consigo fardos e malas de roupa com os quais aliciavam as famílias para casarem suas filhas menores. 
Estes dois parágrafos são elucidativos, porque, suponho, é a partir de exemplos deste género que deve ser entendida a acritude literária em relação aos problemas sociais de uma nação. Não se trata de sobranceria contemporânea, nem sequer de retoricismo nostálgico - até porque ainda hoje se verificam tais práticas que atrasam a vida do país - mas retomo estes factos para contextualizar um dado importante no âmbito deste trabalho: a literatura moçambicana, enquanto instrumento de exaltação de heróis, tem a sua genologia na angústia cantada com a flauta de sofrimento orgânico. Uma espécie de ADN do mal geracional.

Em Estética da criação verbal, Mikhail Bakhtin (2011, p. 265) afirma que o estilema de uma escrita está "indissoluvelmente ligado ao enunciado". Segundo este entendimento, a estética realista em $O$ regresso do morto reside nos liames semânticos do verbo contístico com que o autor interpreta o desassossego, a angústia e a debilidade colectiva das personagens, claramente discerníveis nos vocábulos "mbunhar" 4 e "morrer".

O termo "mbunhar" configura o conceito que nos conduz ao interstício da morte incisiva, pela miséria e pela busca constante do bem-estar. Só que, transcorridos anos mil da liberdade, no território dos contos, tal sofrimento excede os limites da desgraça. O número de crianças na e de rua aumentou drasticamente. As consequências deste derrame de valores humanos são ainda enormes, porquanto se intensificam relatos de sequestros e mortes de pessoas num claro retorno ao império estético da desgraça. Ainda assim, há na efabulação um casamento perfeito do Bem e do Mal, que decorre de associação, numa mesma colectânea, das temáticas da morte (presente em quase todo o perímetro da obra), e do amor subjacente nos contos intitulados "Madalena, xiluva do meu coração" e "Nyeleti".

Lendo estes textos como trajectória retórica deceptiva do passado, não nos surpreende que o narrador axial dos contos nos coaja a uma leitura previsível, ao dizer, em forma de dedicatória, o seguinte: "que a leitura destes contos vos fique um leve, levíssimo sabor à terra. O sabor da nossa terra". Esta recomendação é uma espécie de convite que o autor faz para a celebração do "triunfo da razão e da subjectividade", se nos atermos nas palavras de Francisco Noa (2012, p. 77), extraídas do seu Perto do fragmento, a totalidade: olhares sobre a literatura e o mundo. Ou seja, que a moderna sociedade se encarregue de conciliar as ambivalências existentes entre crenças e convicções que sustentam a diversidade do mal.

Em "Ngilina, tu vai morrer", a vida sofrida da protagonista cabe toda no espaço inóspito dos "insultos sempre-sempre", do "trabalhar todo o dia do xicuembo", da imagem de "burro de puxar nholo", das "cicatrizes que deformam a "bochecha", a "boca" e o "nariz" (Cassamo, 1997, p. 13). Estes epítetos são pormenores textuais que configuram uma autêntica detonação da dor que frustra a mundividência de Ngilina, diminuindo- Ihe a chance de disfrutar os resultados da independência e da liberdade. Por outro lado, a realidade da personagem protagonista assume uma conformação densamente

\footnotetext{
4 "Mbunhar" é o mesmo que "chupar o seio vazio", uma espécie de sofrimento genético que surge de geração em geração. Ou seja, o termo procura traduzir o ponto mais alto da pobreza, em que a grande maioria do povo assiste impávida o comboio a passar, e fica a ver poeira, como se costuma dizer na gíria da fome.
} 
propensa à subjectividade de interpretação da vida. Assim, Ngilina denuncia as fragilidades de uma realidade que não é, de per si, um fenómeno celibatário de Suleiman Cassamo, na medida em que o questionamento, as dúvidas, o cepticismo e o medo são uma constante cultural e quase epidémica.

Há uma espécie de "estética da angústia" bachelardiana (1988, p. 25), que está longe de descobrir a felicidade no mundo das personagens de Suleiman Cassamo. $\mathrm{Na}$ sua obra, a angústia deixou de ser um fenómeno factício: as personagens não respiram livremente, porque vivem atormentadas pela incerteza. Vejamos este suspiro angélico da personagem protagonista: "só o xicuembo sabe" (Cassamo, 1997, p. 15). Ngilina vive num mundo onde a reconciliação com o mal só é possível nas alturas. O recurso à evocação judaico-cristã - "xicuembo" - surge em justaposição conflituosa no plano semântico do conto intitulado "Ngilina, tu vai morrer". Aliás, a força semântica do título remete-nos para um exercício de extrapolação de conflitos de significados entre a morte e a vida, o divino e o sofrimento demoníaco, patentes logo no primeiro parágrafo do conto.

Recentemente, a conceituada escritora Paulina Chiziane publicou uma obra intitulada Ngoma Yethu. Há nesse inventário de dados do cultismo moçambicano uma passagem muito interessante: "quando as pessoas são confrontadas por fenómenos que a sabedoria humana não alcança, buscam explicação nas forças supremas. Quando é desconhecido, inalcançável, dizem logo que é oculto, esotérico, diabólico, demoníaco, belzebu, satânico, por aí em diante" (Chiziane, 2015, p. 199).

"É oculto, esotérico, diabólico, demoníaco, belzebu, satânico" qualquer esclarecimento que procure levar a crer que os maus tratos, o sofrimento e o desassossego que caracterizam a vida das pessoas resultam da configuração do projecto do futuro e do bem-estar. Esta forma de celebração do mal não se esgota nos versículos bíblicos. Ela extravasa os liames demiúrgicos da verosimilhança, na medida em que se trata de um exercício intertextual que atravessa as narrativas de fractura sociocultural. Os parágrafos subsequentes dissipam qualquer dúvida, porquanto confirmam o estado mórbido das condições humanas na sociedade do conto. Uma das técnicas mais rendosas da narrativa consiste no recurso ao pormenor, um processo que prefigura a estética do microrrealismo ${ }^{5}$ que assinala a literatura moçambicana. Cito um exemplo expansível a grande parte da obra, o segundo parágrafo do conto "Ngilina, tu vai morrer" inserto em O regresso do morto: "assim é maneira que Ngilina fala com o seu coração. Esse seu coração inchado no peito, pesado na garganta, a fechar a boca. Lágrimas caladas molham as faces" (Cassamo, 1997, p. 15). A profunda prostração e lucidez realística, veiculadas pela expressão "Ngilina fala com o seu coração", é retomada de forma mais penetrante e claramente sensível no resto do conto:

o corpo dói, sim, mas dói muito muito o coração. O coração 'stá inchado, vai rebentar no peito. Ngilina, tu vai morrer. Pode ir para casa descansar sofrimento. Mas qual maneira se o pai comeu todo o dinheiro do lobolo no

\footnotetext{
${ }_{5} \mathrm{Tal}$ como a poesia portuguesa (Ferreira, 2012, p. 250), o conto moçambicano é densamente caracterizado pela estética do microrrealismo, pelo facto de privilegiar os aspectos de natureza sensorial, visual e táctil.
} 
nthonthontho (sic) e no vinho do monhé da vila? Yotatanéé, é melhor não pensar nada. (Cassamo, 1997, p. 17)

A utilidade da descrição dos sentimentos tem que ver com a inscrição subjectiva da pessoa humana. Porém o individualismo adquire acepção social e filosófica quando associado a expressões como "tu vai morrer", "descansar sofrimento", "o pai comeu todo o dinheiro do lobolo". É que, tais sentimentos filosóficos, representativos de realidades culturais e político-ideológicos predominantemente anti-utópicos, são acompanhados por uma tendência para a narrativização da estética da morte, do desassossego e do sofrimento, que, de forma nua e crua, são detectáveis na "literatura objectiva" evocada por Roland Barthes (2009, p. 35).

As acções da personagem protagonista, o sofrimento que a vida the proporcionou enquanto mulher que vive à beira do precipício, condensam, num só momento, as maquinações estéticas, racionais e sentimentais do mundo, inscritas no pensamento pessoano, em Livro do desassossego, segundo o qual tudo se "tornou insuportável" (Pessoa, s.d., p. 70). Para a personagem protagonista d'O regresso do morto, até a própria vida se tornou num abismo e num grande fardo: os pais, a casa - a sogra, o marido - o ambiente e a sociedade, tudo lhe "sobrebasta e oprime" (Pessoa, s.d., p. 70); e só a morte lhe desafoga. Esta situação é visível nos diferentes episódios do conto, em que os problemas sociais extravasam os limites de "autorrevelação" (Pessoa, s.d., p. 394), interpretados pelo cume expressivo da morte, que encerra a vida da personagem primordial do conto:

a voz do pilão foge para o mato. A sombra do pilão e da Ngilina cresce, fica comprido. Os seios pequenos na sombra são grandes mas só saltam um mucado só. A sombra também pára. Zombeteira, imita a Ngilina que esfrega saliva nas mãos. Esta e todas as outras sombras crescem silenciosamente, abraçam-se para dançar xigubo do pilão da Ngilina. (Cassamo, 1997, p. 16)

Os substantivos "voz", "sombra" e "seios", que se "abraçam", "silenciosamente" na floresta, levam-me a concluir que a pessoa humana deixa de ser um grémio de socialização, uma mundividência de partilha de valores e de símbolos: ela é apenas um objecto de resistência e de confrontação sibilina; sendo, por conseguinte, muito significativo o facto de se tratar de elementos indicadores de penúria. A semântica da voz é, na literatura, muitas vezes associada à exaltação, e ao grito. A associação do som do pilão e da Ngilina faz uma perfeita simbiose estética na construção de significados literários. A sombra é a penumbra que ofusca o sossego da claridade. Segundo o entendimento filosófico de tradição africana, a sombra é considera a "segunda natureza dos seres e das coisas e é geralmente ligada à morte" (Chevalier \& Gheerbrant, 2010, p. 615). Os seios que crescem na sombra configuram o ilusionismo da narrativa e da vida.

A situação de Ngilina ficou mais complicada quando o marido regou à casa: "naquele dia, quando o marido voltou, a sogra fez queixa. Disse Ngilina 'stava com mufanas no poço quando ia caretar [sic] água! Youé! Aquilo não foi bater não" (Cassamo, 1997, 
p. 17). Essa velha e universal antinomia sogra-nora e vice-versa fez com que o marido batesse na mulher até que "dentes ficou partido" e "quase Ngilina queria morrer" (Cassamo, 1997, p. 17). Dissensões deste género têm sido o foco de mortes precoces e preconceituosas no território do conto; é, na verdade, uma atitude que ressalta dos ritos de casamento $^{6}$, porque repetem o que se passou ngaleso sikhathi ${ }^{7}$, no tempo de forte intensidade de valores sociais; eles reactualizam as práticas primitivas de contacto das tradições.

A morte da protagonista, realisticamente provocada pelo sofrimento, pela debilidade e pelo suicídio, é, num plano de "realismo integral", causada pela degradação de todas as certezas, apesar da possível deriva irónica, a verdade é que durante a maior parte da vida, Ngilina foi tratada como "burra de puxar nholo" pelo marido e pela sogra. Como consequência dessa atitude sub-humana, após o suicídio, no mato, o corpo da finada foi velado pelo "choro da rola" (Cassamo, 1997, p. 18), o que, na minha óptica, exaspera a ruína da moral e falta de respeito pela pessoa humana. Terá sido a "cantiga (...) de rola picando o coração da savana" (Cassamo, 1997, p. 16) a principal causa da desgraça? O certo é que, para Ngilina, "morrer é mesmo bom", porque "tudo acaba". Está claramente explicado: a morte surge como efeito de um mecanismo fatalista que recai sobre a estrutura mitológica que passou a ser o modus vivendi da sociedade.

E esta morte já estava, de antemão, previsível. No conto que dá título ao livro de Suleiman Cassamo - "O regresso do morto" -, a acção diegética é claramente explícita, ao sublinhar que "os mortos (...) trazem a cruz pesada da sua própria tumba" (Cassamo, 1997, p. 81). Ou seja, a morte é uma realidade insuprível e inegável. O que é intrigante nesta morte é o facto de ela ser consequência de [ti]ndzava ${ }^{8}$ (Cassamo, 1997, p. 82) protagonizadas pela sogra, queixando-se ao filho da segnícia da nora: "preguiçosa, preguiçosa, preguiçosa. Todo o dia do xicuembo" (Cassamo, 1997, p. 17). Nessas queixas infundadas, a sogra evoca "o lobolo que o filho gastou" (Cassamo, 1997, p. 17), o que mostra que a mulher é encarada sob todas as formas de exploração e desprezo; ela é vendida, à nascença, nas sociedades tradicionais moçambicanas.

Para recriar os pensamentos que imaginam o mito da morte, deve-se ter em conta a fisiologia de toda a realidade tradicional que envolve a vida numa perspectiva. Tanto cheirosa, como advoga Filimone Meigos (2015, p. 184), na sociologia da emoção, a mentira escamoteia a razão, prejudicando as relações interpessoais. Vejamos um exemplo pedagógico muito interessante: a lacuna criada pela fractura social é preenchida pelo embalo da "rola" e pela espessura fria da floresta onde ocorreu o suicídio. Porém, nada

\footnotetext{
${ }^{6}$ Quando uma donzela se casa, os seus familiares dão recomendações profundas, primeiro em forum restrito comandado pelas tias (educadoras tradicionais da mulher), segundo, durante o momento de entrega da noiva ao futuro esposo, através de canções e sermões com forte cunho sentimental. Estes momentos são primordiais para a tomada de decisão por parte da mulher e do homem, se pretendem viver juntos em comunhão espriritual, ou não. É, na verdade, o momento de declaração mútima e intimista do amor.

7 Expressão Zulo que significa "naquele tempo", o tempo mítico e histórico, o tempo das grandes tradições.

${ }^{8}$ Embuste, intriga, mentira subversão feita pela sogra. Filimone Meigos escreve, no seu Ensaio sobre a mentira e a inveja Q outras coisas $(2015$, p. 5), que "a mentira ocorre nos rapports sociaux diários". Na verdade, a mentira passou a ter um espaço privilegiado na sociologia do senso comum, da mentira e da inveja.
} 
surpreende, se tomarmos em linha de conta que, como afirma Gaston Bachelard (2008, p. 192) em A terra e os devaneios da vontade: ensaio sobre a imaginação das forças, "o universo sublunar" compreende o "reino mineral", o "reino vegetal" e o "reino animal", que se complementam mutuamente. Nesta complementaridade, o "choro da rola" surge como espécimen ancilar dos devaneios do luto, tendo em conta os valores sociais que agrega na exegese.

A proposição "o regresso do morto" substantiva um absurdo pragmático no contexto da crítica literária. Segundo a concepção de Jean Chevalier e Alian Gheebrant (2010, p. 460), e tendo em conta o entendimento simbólico do enunciado, "a morte é um aspecto perecível e destruidor da existência". Por isso, celebrar o regresso de um morto pode transmitir vários níveis de entendimento. Mas a destruição nunca deve ser motivo de celebração apoteótica. A destruição deve ser chorada e combatida por todos.

Do ponto de vista metafísico, a morte no território do conto é encarada de forma diferente em relação à visão ocidental. Nas sociedades étnicas, os mortos não morrem. Pelo contrário, emigram para um mundo imaginário, coberto de símbolos e magias, para um mundo que constitui a metáfora do cosmos real, mergulhado no terreno da mitologia. Por isso, embora a morte seja louvada com lágrimas e dor, ela é muito celebrizada ao nível das sociedades tradicionais. Neste ponto de vista, há uma contradição exponencial que reside no facto de a morte ser, por um lado, a expressão da dor profunda e, por outro, representar a configuração da metáfora dessa dor num mundo onírico, num paraíso do imaginário da sociedade. Ou seja, nas sociedades tradicionais africanas, a morte reifica as estruturas antropológicas e o devir das comunidades étnicas.

Como afirmei no início, e como tem sido reiteradamente referenciado pela crítica nacional e estrangeira, $O$ regresso do morto é uma colectânea de contos de afirmação sociocultural moçambicana, e, consequentemente, os seus alicerces ideológicos emanam da competência autoral de Suleiman Cassamo, interessado em circunscrever um universo sociopolítico e estético de raiz autóctone, em consonância, portanto, com o mecanismo de construção do logos da civilização identitária.

São, indubitavelmente, visíveis e actuantes os realemas de denúncia empenhada - o machismo, a miséria, a violência irracional, a ruina do ser humano. Não parece, no entanto, que resida nesse domínio a intenção expressiva do texto. Por um lado, os factores de denúncia - mormente a crueza do poder do homem contra a mulher submissa e a opressão escatológica das leis étnicas, que não se confundem com a justiça -, tanto definem o campo de actuação estético-artística de autores como Orlando Mendes [com a sua obra fabulosa Portagem (1981)], Mia Couto9 ${ }^{9}$ Paulina Chiziane, João Paulo Borges Coelho, e outros. A particular representação da mulher lobolada, por exemplo, ser a personagem principal das narrativas pós-modernas, por outro lado; as grandes questões que motivam a reflexão poético-filosófica da personagem fazem parte das preocupações essenciais, partilhadas pela consciência humana, independentemente das circunstâncias espaciotemporais. Creio, portanto, que mesmo num plano de afirmação

9 O seu recente romance Mulheres de cinza (Couto, 2015) retoma com mais clarividência esse poder machista do homem sobre a mulher, simplesmente considerada objecto de venda ou máquina de procriação. 
da literatura moçambicana, a amplitude semântica da obra cassimoniana constitui um elemento muito importante da afirmação estético-literário. Ou seja, sem perder os valores idiossincráticos da microficção, alcança, pela qualidade artística, o patamar universal das grandes narrativas. Penso ser por isso que interessa a todas as grandes obras e a todos os verdadeiros escritores. Suleiman Cassamo, com o seu Le retour du mort, redefine o espaço complexo da alma humana.

\section{FinANCIAMENTO}

Artigo desenvolvido no contexto do projeto "Memories, cultures and identities: how the past weights on the present-day intercultural relations in Mozambique and Portugal?", financiado pela Rede Aga Khan para o Desenvolvimento e pela Fundação para a Ciência e Tecnologia.

\section{REFERÊNCIAS}

Bachelard, G. (1996). A poética do devaneio . São Paulo: Martins Fontes.

Bachelard, G. (2008). A terra e os devaneios da vontade: ensaio sobre a imaginação das forças. S. Paulo: Martins Fontes.

Bakhtin, M. (2011). Estética da criação verbal. São Paulo: Martins Fontes.

Barthes, R. (2009). Ensaios críticos. Lisboa: Edições 70.

Benjamin, W. (2012). Sobre arte, técnica, linguagem e política. Lisboa: Antropos.

Cassamo, S. (1997). O regresso do morto. Alfragide: Editorial Caminho.

Chevalier, J.-C. \& Gheerbrant, A. (2010). Dicionário dos símbolos. Lisboa: Teorema.

Chiziane, P. \& Martins, M. (2015). Ngoma Yethu: o curandeiro e o novo testamento. Maputo. Índico Editores.

Ernesto, M. G. G. (2002). Morte e solidão em a velha e a aranha. União dos escritores angolanos: críticas $Q$ ensaios. Retirado de http:// www. uea-angola.org/artigo. cfm?ID=634.

Ferreira, A. M. (2012). Sinais de ruína na poesia de Joaquim Manuel Magalhães. In A. M. Ferreira, Sinais de Cinza: estudos de literatura (pp. 243-270). Braga: Ópera Omnia.

Martins, M. de L. (2011). Média e melancolia - o trágico, o grotesco e o barroco. In M. Acciaiuoli \& M. A. Babo (Eds.), Arte a melancolia (pp. 53-65). Lisboa: Instituto de História da Arte / Estudos de Arte Contemporânea e Centro de Estudos de Comunicação e Linguagens. Retirado de http://hdl.handle. net/1822/24106

Martins, M. de L. (2013). O corpo morto: mitos, ritos e superstições. Revista Lusófona de Estudos Culturais, 1(1), 109-134. Retirado de http://hdl.handle.net/1822/29225

Meigos, F. (2015). Ensaio sobre a mentira e a inveja a outras coisas. Maputo: Lithangu Editora.

Mendes, O. (1981). Portagem. Coimbra: Edições 70.

Noa, F. (2014). Perto do fragmento, a totalidade: olhares sobre a literatura e o mundo. Maputo: Ndjira. 
Pessoa, F. (s.d.). Livro do desassossego. S. Paulo: Editora Brasiliense.

\section{NOTA BIOGRÁFICA}

Martins José Chelene Mapera, moçambicano, Doutor em Estudos Culturais pelas Universidades de Aveiro e do Minho, Director da Faculdade de Ciências Sociais e Humanidades, na Universidade Zambeze, professor de Sociologia da Cultura, no Curso de Doutoramento em Língua, Cultura e Sociedade, lecciona os módulos de Literatura Cabo-verdiana e Guineense e Interacções e Práticas Discursivas nos cursos de mestrado e doutoramento, da Universidade Pedagógica. Lecciona, igualmente, as disciplinas de Linguística do Discurso e Português Avançado, no curso de mestrado em Literatura e Língua Portuguesa; Semiótica, Semiologia da Comunicação e Imagem do Discurso, no curso de licenciatura em Ciências da Comunicação, na Universidade Zambeze. Publicou vários artigos científicos pela revista Forma Breve, da Universidade de Aveiro, publicou Realismo e lirismo, em Terra sonâmbula, de Mia Couto, e Chuva braba, de Manuel Lopes (2015), tese de Doutoramento; Poema aberto e a tela da diversidade (2017); Cinzas de cão: ensaios críticos de literatura (2018).

Email: mmapera@uz.ac.mz; jose.mapera@ua.pt

Morada: Universidade de Zambeze, Beira, Moçambique

* Submetido: 04-09-2018

* Aceite: 05-01-2019 